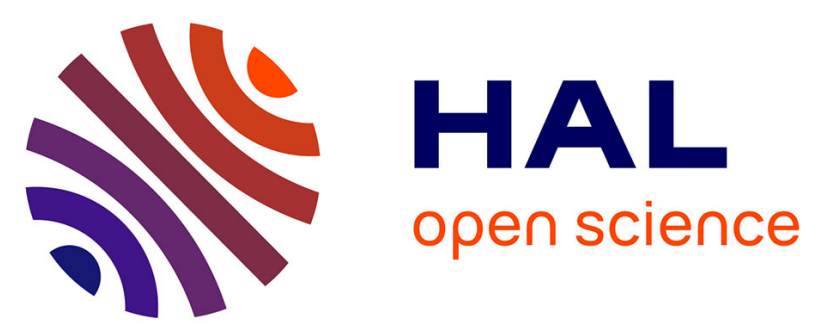

\title{
AN UPDATE OF OSCILLATOR STRENGTHS AND PHOTOIONISATION CROSS SECTIONS FOR THE Be ISOELECTRONIC SEQUENCE
}

J. Tully, M. Seaton, K. Berrington

\section{- To cite this version:}

J. Tully, M. Seaton, K. Berrington. AN UPDATE OF OSCILLATOR STRENGTHS AND PHOTOIONISATION CROSS SECTIONS FOR THE Be ISOELECTRONIC SEQUENCE. Journal de Physique IV Proceedings, 1991, 01 (C1), pp.C1-169-C1-178. 10.1051/jp4:1991120 . jpa-00249758

HAL Id: jpa-00249758

https://hal.science/jpa-00249758

Submitted on 1 Jan 1991

HAL is a multi-disciplinary open access archive for the deposit and dissemination of scientific research documents, whether they are published or not. The documents may come from teaching and research institutions in France or abroad, or from public or private research centers.
L'archive ouverte pluridisciplinaire HAL, est destinée au dépôt et à la diffusion de documents scientifiques de niveau recherche, publiés ou non, émanant des établissements d'enseignement et de recherche français ou étrangers, des laboratoires publics ou privés. 


\title{
AN UPDATE OF OSCILLATOR STRENGTHS AND PHOTOIONISATION CROSS SECTIONS FOR THE BE ISOELECTRONIC SEQUENCE
}

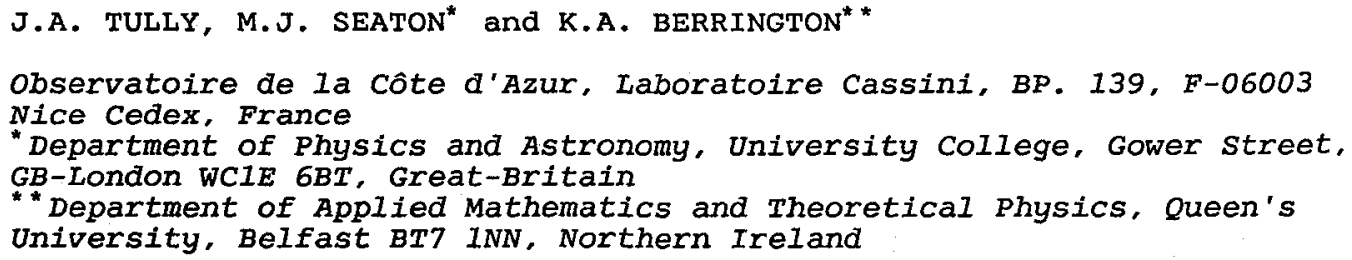

Résumé - Nous présentons une synthèse des travaux récemment publiés pour la photoabsorption par les ions berylliumoïdes, en soulignant notre propre étude des transitions lié-lié et liélibre dans 15 membres de la séquence: $\mathrm{Be}$ à $\mathrm{Si}^{+10}, \mathrm{~S}^{+12}, \mathrm{~A}^{+14}, \mathrm{Ca}^{+16}$ et $\mathrm{Fe}^{+22}$. Nos calculs sont basés sur l'approximation quantique du couplage fort ('close coupling') dans laquelle on tient compte seulement des interactions électrostatiques. Nous avons identifié 1814 termes $L S$ et nous avons déterminé leurs énergies. Les forces d'oscillateur pondérées (valeurs $g f$ ) pour 33030 transitions dipolaires électriques ont été évaluées. D'autre part nous avons calculé 1554 sections efficaces de photoionisation à partir des niveaux au-dessous du premier seuil d'ionisation. Des pas d'énergie suffisament petits ont été utilisés pour pouvoir délinéer la plupart des résonances d'autoionisation qui perturbent les sections. La photoexcitation du cœur produit de grandes résonances d'autoionisation du type PEC; celles-ci dominent beaucoup de sections efficaces pour Be et les ions faiblement ionisés. Nous donnons des exemples sélectionnés parmi nos données et nous les comparons avec les travaux d'autres chercheurs.

\begin{abstract}
We summarise recent work for photoabsorption by beryllium-like ions, giving particular emphasis to our own study of bound-bound and bound-free transitions in the following members of the sequence: $\mathrm{Be}$ to $\mathrm{Si}^{+10}, \mathrm{~S}^{+12}, \mathrm{~A}^{+14}, \mathrm{Ca}^{+16}$ and $\mathrm{Fe}^{+22}$. Our calculations are based on the quantal close-coupling approximation in which only electrostatic interactions are taken into account. A total of 1814 LS terms have been identified and their energies determined. Weighted oscillator strengths ( $g f$ values) for $\mathbf{3 3 0 3 0}$ electric dipole transitions amongst these levels have been evaluated. We have also calculated cross sections for photoionisation from 1554 levels lying below the first ionisation threshold. Photoexcitation of the core produces large PEC resonances; these dominate many of the cross sections for Be and the less highly ionised ions. We give selected samples of our data and make comparisons with the work of other investigators.
\end{abstract}




\section{1 -. INTRODUCTION}

At the last Atomic Data Workshop at St Catherine's College Oxford in $1987 / 1 /$ there were several reviews assessing the currently available methods and data for photoionisation cross sections. The purpose of the present review is to provide an update on those reviews for the beryllium isoelectronic sequence, and to describe recent calculations of $f$ values and photoionisation cross sections for the Opacity Project $/ 2 /$.

Two reviews in $/ 1 /$ are particularly relevant here. Butler, Le Dourneuf and Zeippen presented a complete bibliography for the photoionisation of atoms and ions covering the period 1970-1987, while Saraph selected and described the more reliable methods used to provide the data. As an update, we present in Table 1 a summary of references on both $f$ values and photoionisation cross sections for the Be-sequence in the period 1987-1990.

Table 1 - Work on the Be sequence for the period 1987-1990: energy levels $E$, oscillator strengths $f$ and photoionisation cross sections $\sigma$.

\begin{tabular}{lllll}
\hline Authors & Ref. & Comment & Data & Ions \\
\hline Allard et al. & $/ 3 /$ & Review & $f$ & $\mathrm{C}^{+2}, \mathrm{~N}^{+3}, \mathrm{O}^{+4}$ \\
Lang et al. & $/ 4 /$ & Experimental & $f$ & $\mathrm{~N}^{+3}, \mathrm{O}^{+4}, \mathrm{Ne}^{+6}$ \\
Osanai et al. & $/ 5 /$ & Theoretical & $E$ & $\mathrm{Be}$ \\
Snitchler et al. & $/ 6 /$ & Theoretical & $E$ & $\mathrm{Be}$ \\
Tully et al. & $/ 7 /$ & Theoretical & $\sigma$ & $\mathrm{B}^{+}$ \\
Tully et al. & $/ 8 /$ & Theoretical & $E, f, \sigma$ & $\mathrm{Be}-\mathrm{Si}^{+10}, \mathrm{~S}^{+12}, \mathrm{~A}^{+14}, \mathrm{Ca}^{+16}, \mathrm{Fe}^{+22}$ \\
\hline
\end{tabular}

\section{2 - ATOMIC DATA FOR OPACITY CALCULATIONS: THE Be-SEQUENCE}

We have recently calculated a large amount of atomic data for beryllium-like ions $/ 8 /$. These are for use in an ambitious programme known as the OPACITY PROJECT, the aim of which is to determine stellar envelope opacities $/ 2 /$. Here we summarise our work and make comparisons with the results of independent calculations and experiment. Further details and comparisons are given in $/ 8 /$.

Wave functions for the bound and continuum states of 4-electron atomic systems were generated by a non-relativistic close-coupling approximation as formulated and programmed in the Opacity Project R-matrix code $/ 9 /$.

We assumed that the atom-radiation interaction is sufficiently weak to permit the use of first order perturbation theory in order to compute bound-bound and bound-free oscillator strengths. These quantities enable monochromatic absorption coefficients to be derived and are also essential for determining mean opacities such as Rosseland's /10/.

We included the first five Li-like target states (viz. $1 s^{2} 2 s, 2 p, 3 s, 3 p, 3 d$ ) in the R-matrix opacity code. In this way we generated atomic data for the Be-like ions $\mathrm{C}^{+2}, \mathrm{~N}^{+3}, \mathrm{O}^{+4}, \mathrm{Ne}^{+6}, \mathrm{Na}^{+7}, \mathrm{Mg}^{+8}, \mathrm{Al}^{+9}, \mathrm{Si}^{+10}$, $\mathrm{S}^{+12}, \mathrm{~A}^{+14}, \mathrm{Ca}^{+16}, \mathrm{Fe}^{+22}$ of astrophysically abundant elements with atomic number $Z \leq 26$. In addition to these ions we also obtained data for $\mathrm{Be}, \mathrm{B}^{+}$and $\mathrm{F}^{+5}$.

In the next two subsections we review a selection of these new data for Be sequence $f$ values and photoionisation cross sections. 


\section{1 - OSCILLATOR STRENGTHS}

$f$ values were not reviewed in the last Atomic Data Workshop / $1 /$ but will be considered here. In our Opacity Project calculation /8/ we calculated $g f$ values in fifteen members of the Be isoelectronic sequence for all electric dipole transitions between a total of 1814 bound $L S$ terms having $S=0,1 ; L=0,1,2$, 3,4 (even and odd parity) and $\nu \leq 10.1$, where $\nu$ is the effective quantum number relative to the lowest coupled Li-like target state. This represents a total of 33030 oscillator strengths.

The difference between the length $\left(f_{\mathrm{L}}\right)$ and velocity $\left(f_{\mathrm{V}}\right)$ forms of the oscillator strength often provides an indication of the accuracy of theoretical calculations. If exact wavefunctions are used then $f_{\mathrm{L}}=f_{\mathrm{V}}$. Since Opacity Project calculations are based on a collision formulation, we believe that our length results are likely to be more reliable than our velocity ones. This is because the length form samples wavefunctions at larger radial distances where ours are expected to be more accurate. Only the length forms of the $g f$ values and photoionisation cross sections are used to calculate opacities in the Opacity Project. Furthermore, we do not store the velocity form of the cross sections nor do we calculate $g f_{\mathrm{V}}$ when the transition energy is too small.

Because we compute such a large number of $g f$ values, it is not practicable to compare the length and velocity results for all transitions. However we can make a graphical comparison to show the quality of agreement that our calculation achieves. This we do by plotting $\log \left|g f_{\mathrm{L}}\right|$ against $\log \left|g f_{\mathrm{V}}\right|$ for all transitions in a given ion. Data points which lie on or near the diagonal signify transitions for which the agreement is good. Figures $1 \mathrm{a}, 1 \mathrm{~b}$ and $1 \mathrm{c}$ are for three representative cases, namely Be I, Ne VII and Fe XXIII. It can be seen from these plots that the greatest differences between length and velocity oscillator strengths usually occur when both $\log \left|g f_{\mathrm{L}}\right|$ and $\log \left|g f_{\mathrm{V}}\right|$ are very small.

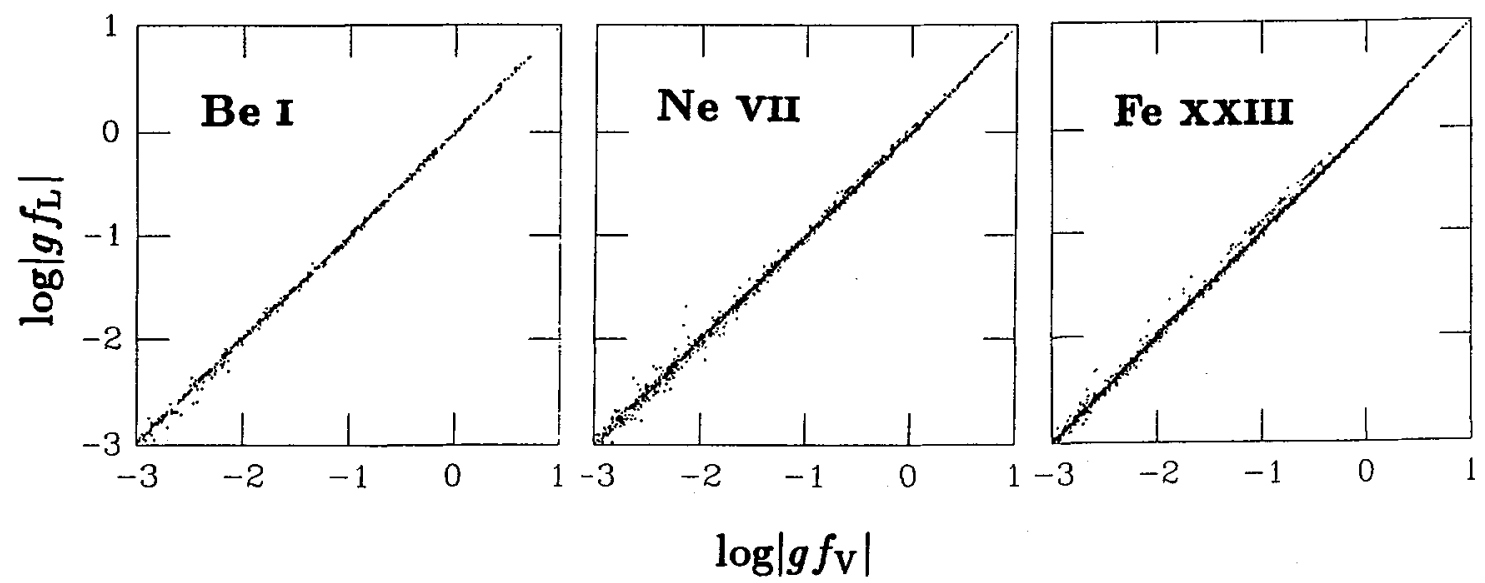

Fig. 1 - Opacity Project: $\log \left|g f_{\mathrm{L}}\right|$ versus $\log \left|g f_{\mathrm{V}}\right|$ for all transitions considered in Be I, Ne VII and Fe XXIII.

Allard et al. /3/ have assessed data for C III, N IV and $\mathrm{OV}$ and they reported on this in the present workshop. Their recommended values are based on weighted means of available $f$ values including our own /8/. This procedure works well for most transitions and their recommendations are generally close to our values. However there is one transition, namely $2 \mathrm{p}^{2}{ }^{1} \mathrm{D}-2 \mathrm{~s} 3 \mathrm{p}^{1} \mathrm{P}^{\circ}$ in $\mathrm{C}$ III, for which Allard and 
her co-workers included data from /11/ that has recently been shown to be invalid (see below). This affects their recommended $f$ value significantly; but it is an exception and Allard et al. are to be congratulated on assessing such a vast amount of data.

The most recent experimental data are from plasma measurements by Lang et al. /4/ and in Table 2 we compare their transition rates (i.e. $A$ values) with the theoretical predictions of Glass $/ 12 /$, Hibbert /13/ and the Opacity Project /8/. There is excellent agreement between the theoretical results which also agree with most of the experimental data. But there are worrying cases where the theoretical results lie outside the experimental error bars. For example, $2 \mathrm{~s} 3 \mathrm{~s}{ }^{3} \mathrm{~S}-2 \mathrm{~s} 3 \mathrm{p}{ }^{3} \mathrm{P}^{\circ}$ and $2 \mathrm{p}^{2}{ }^{3} \mathrm{P}-2 \mathrm{~s} 3 \mathrm{p}{ }^{3} \mathrm{P}^{\circ}$ in $\mathrm{N}$ IV and Ne VII and $2 \mathrm{~s} 3 \mathrm{p}^{1} \mathrm{P}^{\circ}-2 \mathrm{~s} 3 \mathrm{~d}^{1} \mathrm{D}$ in $\mathrm{O} \mathrm{v}$. We have no explanation for this and can only stress the fact that the CIV3 and OP calculations are independent, use different methods and approximations and yet produce results which agree remarkably well.

Table 2 - Comparison of experimental /4/ and theoretical $A$ values in $\mathrm{s}^{-1}$; a, Opacity Project results $/ 8 /$; $\mathrm{b}$, CIV3 results for $\mathrm{N} I V, \mathrm{Ne} V I I / 12 /$ and $\mathrm{O} V / 13 /$.

\begin{tabular}{|c|c|c|c|c|}
\hline Ion & Transition & Experiment & $\mathbf{a}$ & b \\
\hline$N_{\text {IV }}$ & $\begin{array}{l}2 s 3 p^{3} p^{\circ}-2 s 3 d^{3} D \\
2 s 2 p{ }^{3} p^{o}-2 s 3 d^{3} D \\
2 s 3 p{ }^{1} P^{o}-2 s 3 d^{3} D \\
2 s 2 p{ }^{1} P^{o}-2 s 3 d^{1} D \\
2 s 3 s s^{3} S-2 s 3 p{ }^{3} P^{\circ} \\
2 p^{2}{ }^{3} P-2 s 3 p^{3} P^{\circ}\end{array}$ & $\begin{array}{l}1.0(7) \dagger \pm 32 \% \\
3.0(10) \pm 10 \% \\
8.5(7) \pm 24 \% \\
1.7(10) \pm 11 \% \\
0.23(8) \pm 38 \% \\
8.8(7) \pm 7 \%\end{array}$ & $\begin{array}{l}1.05(7) \\
3.03(10) \\
6.72(7) \\
1.84(10) \\
1.07(8) \\
1.48(7)\end{array}$ & $\begin{array}{l}1.11(7) \\
3.03(10) \\
6.32(7) \\
2.03(10) \\
1.06(8) \\
1.42(7)\end{array}$ \\
\hline Ov & $\begin{array}{l}2 s 3 p^{3} p^{\circ}-2 s 3 d^{3} D \\
2 s 2 p{ }^{3} p^{\circ}-2 s 3 d^{3} D \\
2 s 3 p{ }^{1} p^{\circ}-2 s 3 d^{1} D \\
2 s 2 p{ }^{1} P^{\circ}-2 s 3 d^{1} D \\
2 s 3 s{ }^{1} S-2 s 3 p{ }^{1} p^{\circ} \\
2 s^{2}{ }^{1} S-2 s 3 p{ }^{1} p^{\circ} \\
2 p^{2}{ }^{1} D-2 s 3 p p^{1} p^{\circ} \\
\text { Line ratiof }\end{array}$ & $\begin{array}{l}1.6(7) \pm 28 \% \\
6.2(10) \pm 13 \% \\
1.9(8) \pm 26 \% \\
4.2(10) \pm 13 \% \\
2.7(7) \pm 25 \% \\
2.8(10) \pm 11 \% \\
1.4(9) \pm 31 \% \\
6.1 \pm 26 \%\end{array}$ & $\begin{array}{l}1.40(7) \\
6.89(10) \\
0.92(8) \\
4.28(10) \\
1.80(7) \\
2.95(10) \\
2.17(9) \\
2.67\end{array}$ & $\begin{array}{l}1.49(7) \\
6.85(10) \\
0.87(8) \\
4.48(10) \\
1.79(7) \\
2.92(10) \\
2.35(9) \\
2.52\end{array}$ \\
\hline Ne VII & $\begin{array}{l}\text { Line ratio } \\
2 s 3 s^{3} S-2 s 3 p{ }^{3} P^{\circ} \\
2 p^{2}{ }^{3} P-2 s 3 p p^{3} P^{o}\end{array}$ & $\begin{array}{l}2.4(-4) \pm 19 \% \\
4.4(8) \pm 8 \% \\
1.2(8) \pm 18 \%\end{array}$ & $\begin{array}{l}2.27(-4) \\
2.06(8) \\
3.76(8)\end{array}$ & $\begin{array}{l}2.37(-4) \\
2.08(8) \\
3.6(8)\end{array}$ \\
\hline
\end{tabular}

In an outstanding paper published almost 20 years ago, Nussbaumer $/ 11 /$ gave $A$ values for 16 transitions amongst levels of $2 \operatorname{snl}(n=2,3)$ and $2 \mathrm{p}^{2}$ in 10 ions ranging from $\mathrm{C}$ III to Fe XXIII. His calculations made use of an early version of the well known SUPERSTRUCTURE code /14/ with some allowance for relativistic effects. (The code included an ad hoc $Z$-dependent modification of the spin-orbit interaction.) The $A$ values were obtained from theoretical line strengths using observed wavelengths. In Table 3 we compare some of Nussbaumer's results with ours for the ions O V, Ne VII, Mg IX and Fe XXIII. The four transitions considered are within the $n=2$ complex. 
Table 3 - Electric dipole transitions within the $n=2$ complexes of $\mathrm{O} \mathrm{V}, \mathrm{Ne}$ VII, $\mathrm{Mg}$ IX and Fe XXIII. A comparison of length gauge $A$ values from OP (Opacity Project $/ 8 /$ ) with those of $N$ (Nussbaumer /11/). Theoretical wavelengths are given in parentheses under OP and observed wavelengths from Kelly's tabulation /16/ under $N$, except where otherwise indicated. $A$ is in $10^{8} \mathrm{~s}^{-1}$ and $\lambda$ is in $\mathrm{nm}$.

\begin{tabular}{|c|c|c|c|c|c|c|c|c|}
\hline \multirow[b]{2}{*}{$Z$} & \multicolumn{2}{|c|}{${ }^{3} \mathrm{P}-{ }^{3} \mathrm{P}^{\circ}$} & \multicolumn{2}{|c|}{${ }^{1} \mathrm{P}^{\circ}-{ }^{1} \mathrm{~S}$} & \multicolumn{2}{|c|}{${ }^{1} \mathrm{D}-{ }^{1} \mathrm{P}^{\circ}$} & \multicolumn{2}{|c|}{${ }^{1} \mathrm{~S}-{ }^{1} \mathrm{P}^{\circ}$} \\
\hline & OP & $\mathbf{N}$ & OP & $\mathrm{N}$ & OP & $\mathrm{N}$ & OP & $\mathrm{N}$ \\
\hline 8 & $\begin{array}{l}23.04 \\
(75.24)\end{array}$ & $\begin{array}{l}23.3 \\
(76.03)\end{array}$ & $\begin{array}{l}30.05 \\
(62.14)\end{array}$ & $\begin{array}{l}27.4 \\
(62.97)\end{array}$ & $\begin{array}{l}3.28 \\
(138.21)\end{array}$ & $\begin{array}{l}3.62 \\
(137.12)\end{array}$ & $\begin{array}{l}42.19 \\
(75.37)\end{array}$ & $\begin{array}{l}48.0 \\
(77.45)\end{array}$ \\
\hline 10 & $\begin{array}{l}31.76 \\
(55.97)\end{array}$ & $\begin{array}{l}32.5 \\
(56.15)\end{array}$ & $\begin{array}{l}40.85 \\
(46.19)\end{array}$ & $\begin{array}{l}38.5 \\
(46.52)\end{array}$ & $\begin{array}{l}5.77 \\
(98.70)\end{array}$ & $\begin{array}{l}6.73 \\
(97.51)^{\star \star}\end{array}$ & $\begin{array}{l}60.63 \\
(55.18)\end{array}$ & $\begin{array}{l}79.7^{\star} \\
(55.42)^{\star \star}\end{array}$ \\
\hline 12 & $\begin{array}{l}40.29 \\
(44.62)\end{array}$ & $\begin{array}{l}42.0 \\
(44.37)\end{array}$ & $\begin{array}{l}51.48 \\
(36.82)\end{array}$ & $\begin{array}{l}50.1 \\
(36.80)\end{array}$ & $\begin{array}{l}7.41 \\
(76.87)\end{array}$ & $\begin{array}{l}8.31 \\
(74.95)\end{array}$ & $\begin{array}{l}79.00 \\
(43.60)\end{array}$ & $\begin{array}{l}88.3 \\
(43.86)\end{array}$ \\
\hline 26 & $\begin{array}{l}98.71 \\
(18.53)\end{array}$ & $\begin{array}{l}82.9 \\
(16.26)\end{array}$ & $\begin{array}{l}125.0 \\
(15.29)\end{array}$ & $\begin{array}{l}125.0 \\
(13.28)\end{array}$ & $\begin{array}{l}22.08 \\
(30.30)\end{array}$ & $\begin{array}{l}23.2 \\
(22.13)\end{array}$ & $\begin{array}{l}206.7 \\
(17.75)\end{array}$ & $\begin{array}{l}239.0 \\
(14.92)\end{array}$ \\
\hline
\end{tabular}

* Presumably a misprint in /11/

$\star \star$ Bashkin and Stoner /15/

At low atomic number $Z$ the agreement is best $(\sim 1 \%)$ for the ${ }^{3} \mathrm{P}-{ }^{3} \mathrm{P}^{\circ}$ transition; this is no longer true at $Z=26$ where our $A$ value exceeds Nussbaumer's by $18 \%$. This may be due to relativistic effects which our calculation neglects. If we use the observed wavelength $(\lambda=16.26 \mathrm{~nm})$ then the difference increases to over $50 \%$. Our $A$ value for ${ }^{1} \mathrm{P}^{\circ}-{ }^{1} \mathrm{~S}$ exceeds Nussbaumer's by $10 \%$ at $Z=8$ but there is exact agreement when $Z=26$. For the other two singlet transitions there is no apparent $Z$ dependent effect. We find a striking discrepancy between our results and Nussbaumer's for transitions between levels of $2 \mathbf{p}^{2}$ and $2 \mathrm{~s} 3 \mathrm{p}$ which involve 2-electron jumps. A careful investigation by Eissner and Tully (to be published) has shown that Nussbaumer's treatment of these transitions is unsatisfactory owing to the omission of an important spectroscopic configuration.

Fawcett /17/ used a modified version of R. D. Cowan's relativistic Hartree-Fock computer code to obtain a large number of $g f$ values for $n=2-3$ transitions in Be-like ions with $8 \leq Z \leq 26$ and $Z=28$. The $Z$ dependence of some of his results differs from ours. We illustrate this in Fig. 2 by plotting $g f\left(2 \mathrm{~s} 2 \mathrm{p}{ }^{1} \mathrm{P}^{\circ} \rightarrow 2 \mathrm{p} 3 \mathrm{p}^{1} \mathrm{D}\right)$ as a function of $Z^{-1}$. Although Fawcett's $g f$ values follow the upward trend of the OP results for $Z$ less than 16, this changes dramatically with increasing $Z$. Whereas the LS-coupling data points rise smoothly towards the hydrogenic limit of 1.20 at $1 / \mathrm{Z}=0$, Fawcett's $g f$ values appear to decrease linearly. 


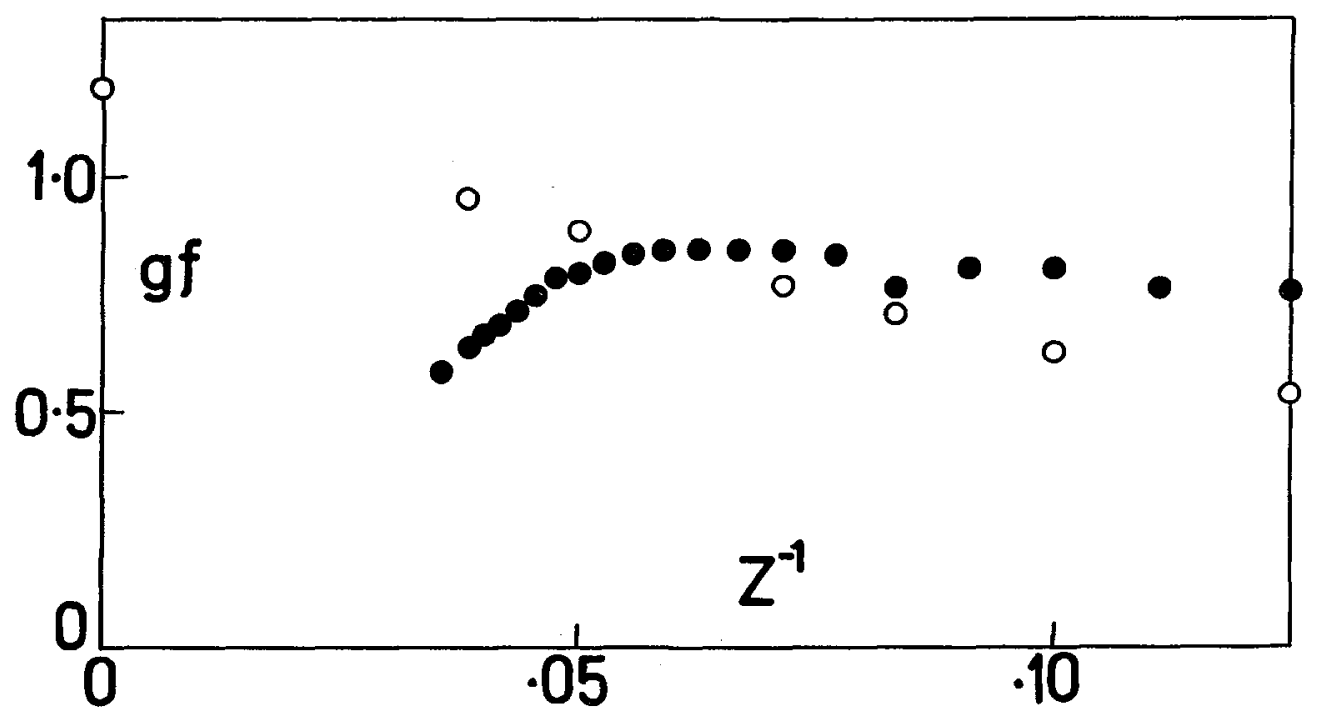

Fig. $2-Z$ dependence of $g f\left(2 \mathrm{~s} 2 \mathrm{p}{ }^{1} \mathrm{p}^{\circ}-2 \mathrm{p} 3 \mathrm{p}{ }^{1} \mathrm{D}\right)$. ० Opacity Project /8/; • Fawcett $/ 17 /$.

\section{2 - PHOTOIONISATION CROSS SECTIONS}

In her review at the last Atomic Data Workshop / $1 /$ in 1987, H. E. Saraph wrote that "unfortunately many data are still only presented in the form of graphs; more effort is required to present data in a form suitable for input to applications programs". A major requirement of the Opacity Project /2/ was to have a complete set of photoionisation data in computer readable form covering all astrophysically important atoms and ions in a range of initial states. This has now been done.

For the Be-sequence we calculated cross sections for photoionising all the even and odd terms with $L \leq 3, S=0$ and $1, \nu \leq 10.1$ (where $\nu$ is the effective principal quantum number relative to the lowest coupled Li-like target state) lying below the first ionisation threshold $/ 8 /$. It was necessary to use a fine energy mesh between the $2 \mathrm{~s}$ and $3 \mathrm{~d}$ thresholds in order to exhibit the complex autoionising structure of each cross section. Above the $3 \mathrm{~d}$ threshold the cross sections are smoothly varying and there a coarse mesh suffices. In this way we obtained a total of 859570 cross section values for photoionisation of 1554 bound states in fifteen members of the beryllium isoelectronic sequence. We now discuss a small selection of these results.

In Fig. 3 we show $\log -\log$ plots of the ground state photoionisation cross section versus photon energy, for $Z=4-14,16,18,20$ and 26 from the Opacity Project $/ 8 /$. As the atomic number $Z$ increases the average size of the cross section decreases and resonance structures become less important.

Previous bound-free calculations have concentrated on absorption by ground state atoms and ions. Most research on the beryllium sequence has involved approximations which exclude the perturbing effects of autoionising resonances. We shall not attempt to make an exhaustive list of all the relevant work in this domain, but only single out the tabulation by Reilman and Manson /18/. This covers many isoelectronic sequences, including that of beryllium, and provides reliable estimates of background cross sections for photoionisation from $2 \mathrm{~s}^{2}{ }^{1} \mathrm{~S}$. 

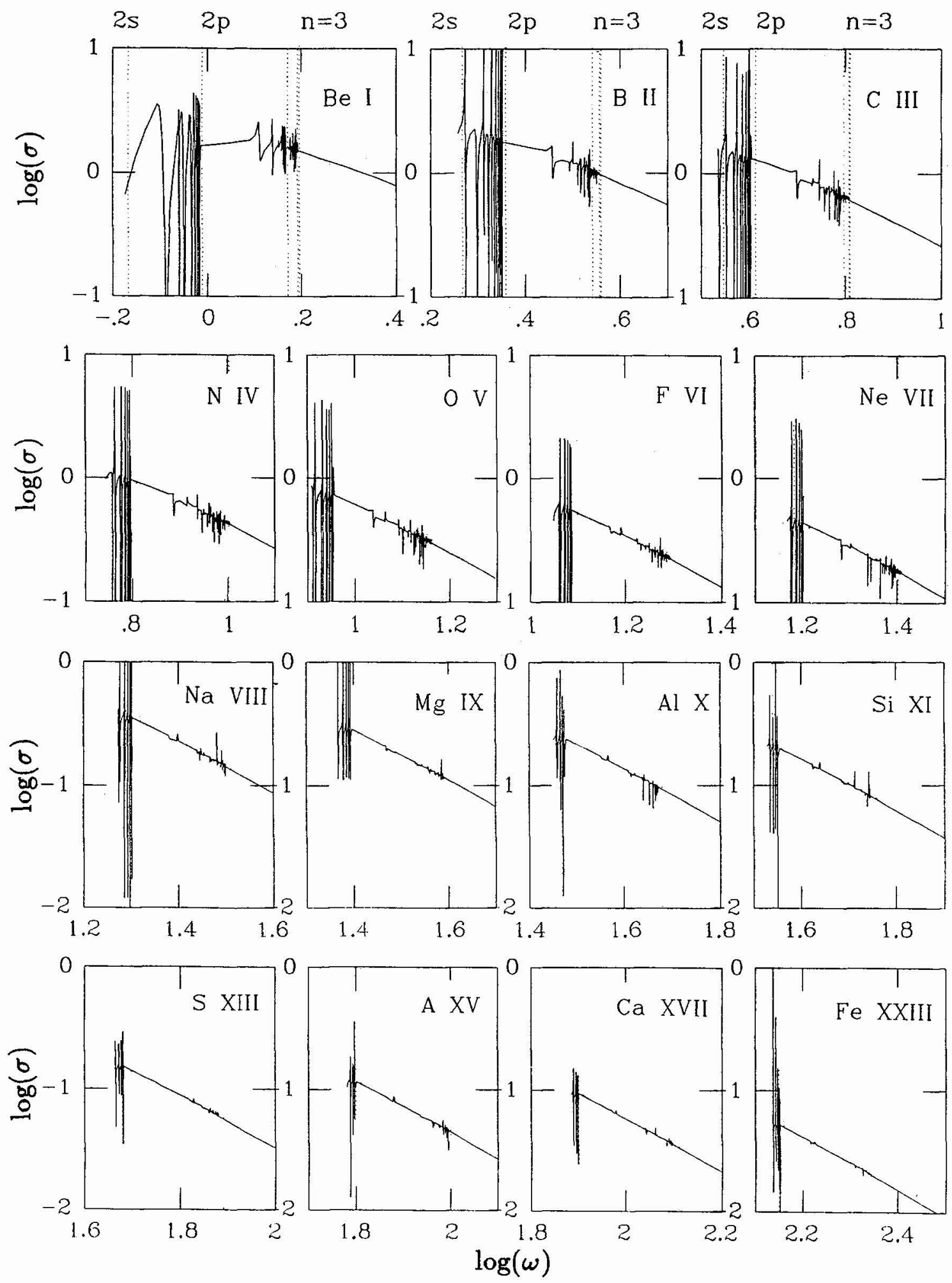

Fig. 3 - Opacity Project: Cross sections for photoionisation of Be-like ions from the $2 \mathrm{~s}^{2}{ }^{1} \mathrm{~S}$ ground state. $\sigma$ is the cross section in Mb and $w$ is the photon energy in Ryd. 
Our results closely resemble those of (i) Dubau and Wells /19/, Moccia and Spizzo /20/ and O'Mahony and Greene /21/ for Be I; (ii) Tully et al. /7/ for B Il and (iii) Bely-Dubau and Dubau /22/ and.Drew and Storey /23/ for C III. This is not surprising since these researchers used similar approximations to ours. We note that $/ 20 /$ and $/ 23$ / also give cross sections for photoionisation from $2 \mathrm{~s} 2 \mathrm{p}^{3} \mathrm{P}^{\circ}$ as well as from the ground state. With the exception of Tully et al. $/ 7 /$, the results are in all cases presented only as graphs which limits their usefulness as input to opacity codes.

The measurements of Esteva and co-workers /24/ and /25/ and Jannitti et al. /26/ provide experimental confirmation of the autoionising resonances which characterise our theoretical cross sections.

An important aim of the Opacity Project was to calculate photoionisation from excited states. It was in this work that a major discovery was made, namely that of the important role of PEC resonances in the cross sections. PEC resonances are caused by PhotoExcitation of a Core electron. They are discussed in ADOC IV /27/ where an analytic profile formula is given for the case of one open channel. Our work /8/ shows that PEC resonances below the $2 \mathrm{p}$ threshold provide important contributions to photoabsorption from excited states of Be-like ions. The resonances arise through transitions of the type $2 \mathrm{~s} n l \rightarrow 2 \mathrm{p} n l$

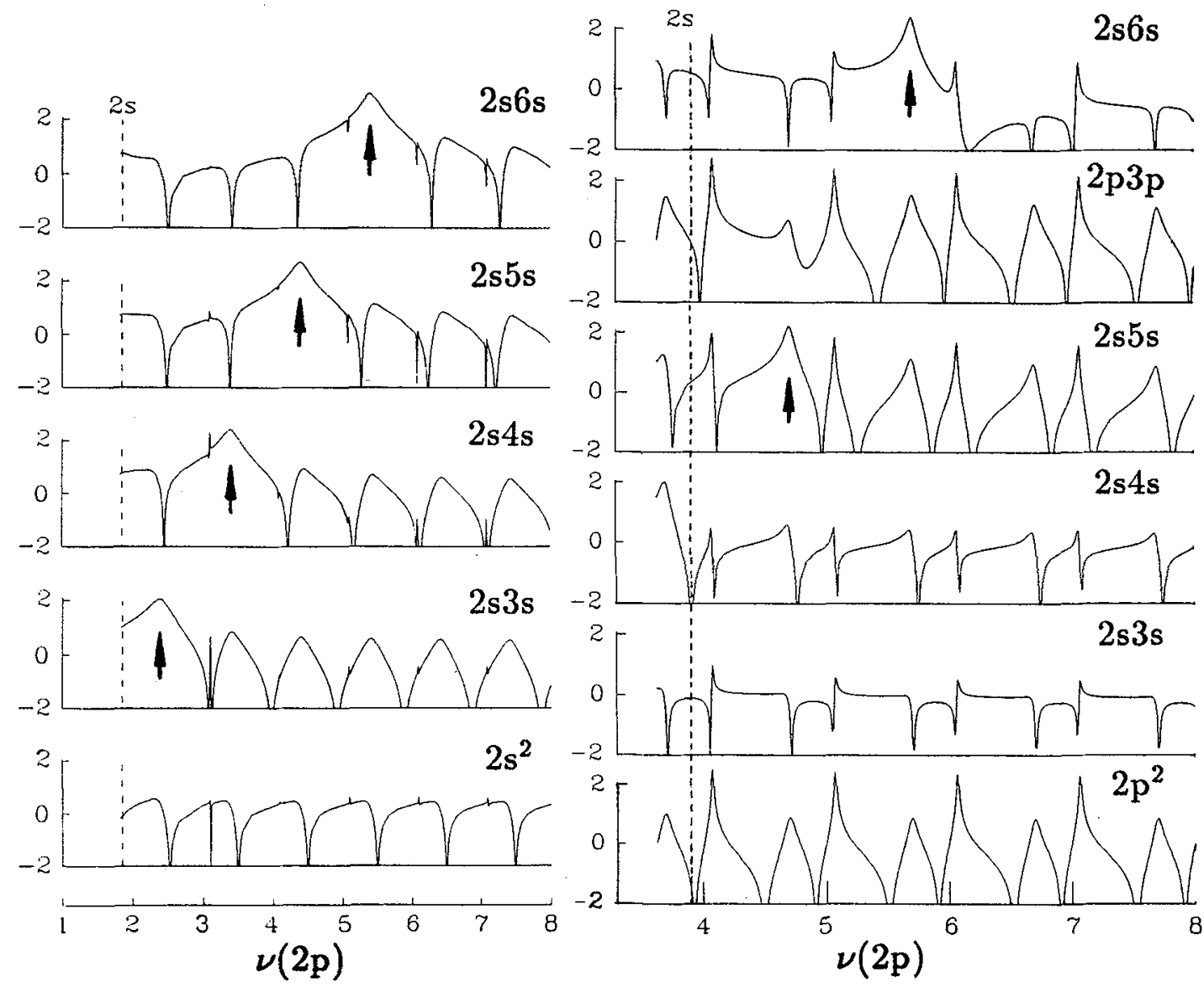

Fig. 4 - Opacity Project: Results showing PEC resonances (signalled by black arrows) in a selection of cross sections for photoionising ${ }^{1} \mathrm{~S}$ states of $\mathrm{Be} I$ and $\mathrm{C} \mathrm{III.} \log (\sigma)$ is plotted against the effective quantum number $\nu(2 \mathrm{p})$ in the interval between the $2 \mathrm{~s}$ and $2 \mathrm{p}$ ionisation thresholds. The cross section $\sigma$ is in $\mathrm{Mb}$. 
followed by Auger decay. In order to autoionise, the $2 \mathrm{p} n l$ level must of course lie above the $2 \mathrm{~s}$ threshold. So it is clear that for the more highly charged ions, PEC resonances will occur only in the cross sections of the more highly excited $2 \mathrm{snl}$ states. This is because an increasing number of $2 \mathrm{p} n l$ states become bound as $Z \rightarrow \infty$.

Fig. 4 shows cross sections for photoionisation from several ${ }^{1} \mathrm{~S}$ levels in Be I and $\mathrm{C}$ III. We plot $\log (\sigma)$ against $\nu(2 p)$, the effective quantum number in the $2 p$ channel. The PEC resonances are signalled by black arrows. For photoionisation from ${ }^{1} \mathrm{~S}$ states there is only one allowed final symmetry, namely ${ }^{1} \mathrm{P}^{\circ}$. The closed channel states giving rise to resonances are $2 \mathrm{p} \nu$ s and $2 \mathrm{p} \nu \mathrm{d}$, where $\nu \equiv \nu(2 \mathrm{p})$. For Be I the $\nu \mathrm{d}$ resonances are very narrow and are not completely resolved in our calculation. The results for ${ }^{1} \mathrm{~S}$ states of beryllium are in good agreement with the formulae given in ADOC IV. For $\mathrm{C}$ III the second ${ }^{1} \mathrm{~S}$ state is $2 \mathrm{p}^{2}$ and below the $2 \mathrm{p}$ threshold the cross section for this state contains practically no non-resonant background. The cross section for $2 \mathrm{~s} 3 \mathrm{~s}$ does not contain a PEC resonance below $2 \mathrm{p}$ because the $2 \mathrm{p} 3 \mathrm{~s}^{1} \mathrm{P}^{\circ}$ state is bound in ions with $Z \geq 6$. PEC resonances for $\mathrm{C}$ III are seen in Fig. 4 only for 2 sns states with with $n \geq 5$.

\section{3 - CONCLUSION}

We note that, apart from a few highly optimised configuration interaction calculations, theoretically determined wavelengths are not of spectroscopic accuracy. However, there is now considerable agreement between the best theoretical calculations and experimental measurements of $f$ values in the Be-sequence, though we noted a few exceptions in Table 4.

There is also substantial agreement between theoretical calculations of the photoionisation cross sections in the Be-sequence, and it would be useful to have more experimental work in this area in order to allow a better discrimination between the various methods.

We note the importance of PEC resonances in the photoionisation of excited states of Be-like ions; these resonances will have a significant effect on opacity calculations and they represent a major advance on previous calculations.

The requirement of applications programs, such as opacity calculations, for computer-readable datasets of $f$ values and photoionisation cross sections is now satisfied with the Opacity Project data. A systematic and highly accurate calculation of photoabsorption data for beryllium-like ions of low $Z$ in many excited states has now been completed /8/. However, for more highly charged ions such as $\mathrm{Fe}^{+22}$ and beyond one needs to take account of relativistic effects in order to achieve high accuracy. 


\section{REFERENCES}

/1/ Proceedings of the Atomic Data Workshop held at St. Catherine's College, Oxford. 1-2 August 1987. Eds. W. Eissner and A. E. Kingston. S.E.R.C. Daresbury Laboratory Report.

/2/ Seaton, M.J., J. Phys. B: At. Mol. Phys. 20 (1987) 6363.

/3/ Allard, N., Artru, M.-C., Lanz, T. and Le Dourneuf, M., Astron. Astrophys. Suppl. Ser. 84 (1990) 563.

/4/ Lang, J., Hardcastle, R.A., McWhirter, R.W.P. and Spurrett, P.H., J. Phys. B: At. Mol. Phys. 20 (1987) 43.

/5/ Osanai, Y., Noro, T. and Sasaki, F., J. Phys. B: At. Mol. Opt. Phys. 22 (1989) 3615.

/6/ Snitchler, G.L. and Watson, D.K., Phys. Rev. A 36 (1987) 1533.

/7/ Tully, J.A., Le Dourneuf, M. and Zeippen, C.J., Astron. Astrophys. 211 (1989) 485.

/8/ Tully, J.A., Seaton, M.J. and Berrington, K.A., J. Phys. B: At. Mol. Opt. Phys. 23 (1990) in press.

/9/ Berrington, K.A., Burke, P.G., Butler, K., Seaton, M.J., Storey, P.J., Taylor, K.T. and Yu Yan, J. Phys. B: At. Mol. Phys. 20 (1987) 6379.

/10/ Rosseland, S., Mon. Not. Roy. Astron. Soc. 84 (1924) 525.

/11/ Nussbaumer, H., Astron. Astrophys. 16 (1972) 77.

/12/ Glass, R., J. Phys. B: Atom. Molec. Phys. 12 (1979) 1633.

/13/ Hibbert, A., J. Phys. B: Atom. Molec. Phys. 13 (1980) 1721; Comput. Phys. Commun. 9 (1975) 141.

/14/ Eissner, W., Jones, M. and Nussbaumer, H., Comput. Phys. Commun. 8 (1974) 270.

/15/ Bashkin, S. and Stoner, J.O., Jr. "Atomic Energy-Level and Grotrian Diagrams". Vol. I. Addenda. (1978) North-Holland Publ. Co., Amsterdam.

/16/ Kelly, R.L., J. Phys. Chem. Ref. Data 16 (1987) Suppl. 1.

/17/ Fawcett, B.C., At. Data Nucl. Data Tables 30 (1984) 1; erratum, 33 (1985) 479.

/18/ Reilman, R.F. and Manson, S.T., Astrophys. Journ. Suppl. 40 (1979) 815; erratum 46 (1981) 115.

/19/ Dubau, J. and Wells, J., J. Phys. B: Atom. Molec. Phys. 6 (1973) 1452.

/20/ Moccia, R. and Spizzo, P., J. Phys. B: At. Mol. Phys. 18 (1985) 3537.

/21/ O'Mahony, P.F. and Greene, C.H., Phys. Rev. A 31 (1985) 250.

/22/ Bely-Dubau, F. and Dubau, J., J. Physique (Paris) 39 (1978) C1-87.

/23/ Drew, J.E. and Storey, P.J., J. Phys. B: At. Mol. Phys. 15 (1982) 2357.

/24/ Esteva, J.M., Thèse Doc. d'Etat (1974) Université Paris XI.

/25/ Esteva, J.M., Mehlman-Ballofet, G. and Romand, J.J., J. Quant. Spect. Radiat. Trans. 12 (1972) 1291. /26/ Jannitti, E., Pinzhong, F. and Tondello, G., Phys. Scr. 33 (1986) 434.

/27/ Yu Yan and Seaton, M.J., J. Phys. B: At. Mol. Phys. 20 (1987) 6409. 